\title{
A Step Forward Towards Heavy Metals in Selected Fruits and Their Effects on Various Body Organs
}

\author{
Haider Ali $^{1}$, Muhammad Ikram ${ }^{1}$, Asim Rehman ${ }^{* *}$, Sadia Akbar ${ }^{1}$, Maria Qamar ${ }^{1}$, Muhammad Bilal $^{1}$, Muqaddas Alam² \\ ${ }^{1}$ Department of Biochemistry, Government College University, Faisalabad, Pakistan \\ ${ }^{2}$ Department of Botany, Government College University, Faisalabad, Pakistan
}

DOI: $10.36348 /$ sijb.2020.v03i04.004

| Received: 20.04.2020 | Accepted: 27.04.2020 | Published: 30.04.2020

*Corresponding author: Asim Rehman

Abstract

Heavy metals toxicity in fruits is a great concern and there is a need for proper understanding of related mechanism like oxidation state and concentration. Few metals can be removed by elimination activities but others interfere in metabolic processes. These heavy metals can also involve in redox reactions, transferring electrons, basic nucleic acid metabolisms, and also being a vital part of several enzyme. Literature sources point out the releasing of such metals in environment by both anthropogenic and natural means. Ingestion of such metals lead to form stable bio toxic compounds by hindering bio reactions of functions as well as mutilating their structures. It may lead to various disorders and induce free radical formation. This review give detail about toxicity and impact on health. Eco toxicity test in addition to chemical concentration monitoring is very useful tool for examining remediation efficiency of such metals in soil.

Keywords: Heavy Metals, transferring electrons, concentration.

Copyright @ 2020: This is an open-access article distributed under the terms of the Creative Commons Attribution license which permits unrestricted use, distribution, and reproduction in any medium for non-commercial use (NonCommercial, or CC-BY-NC) provided the original author and source are credited.

\section{INTRODUCTION}

Metals are those substances that have high malleability, electrical conductivity and luster and these can form cations by losing their electrons voluntarily. Metals are present in earth's crust. Heavy metals referred to those whose density is greater than $5 \mathrm{~g} / \mathrm{cm}^{3}$ and they have adverse effects on living organisms and environment. However, heavy metals are beneficial for living organisms if present in normal amount but if exceeds the threshold level they become toxic. Persistent exposure to these metals has adverse effects. They are remarkable pollutants of environment and have toxicity problems for evolutionary, ecological, environmental and nutritional reasons [19]. Most common heavy metals include chromium, cadmium, lead, copper, zinc and nickel and these all are cause of risks for human and environment. Several sources of these metals are urban runoff, mining, sewage discharge, soil erosion, insecticides and industrial effluents [28].

\section{Heavy metals in mango}

Fruits are the essential part of our diet as they provide minerals and vitamins, the vital components require for human health. Mangiferaindica (mango) has been produced in 90 countries throughout the world its production capacity in Pakistan is 1 million tons per year [2].

$\mathrm{Pb}, \mathrm{Cr}, \mathrm{Ni}$ and $\mathrm{Cd}$ are the trace elements that are non-biodegradable thus they have capability to deposit in different body organs [9]. Waste water is polluted with heavy metals hence contaminate the crops grown in it. The significant amount of these heavy metals accumulates in various tissues [29].

Heavy metals emitted from vehicles and industries are deposited on the surface of vegetables and fruits. Human health might be severely damaged by these heavy metals including impaired psycho-social behavior, neurological disorders, decrease in immunity and cancer of upper gastrointestinal tract [14].

Saeed elaborated that heavy metals ( $\mathrm{Fe}, \mathrm{Pb}, \mathrm{Cd}$ and $\mathrm{Ni}$ ) concentration in mangoes from Multan is higher as compared to other mango producing areas like Rahim yar khan and Mir purkhas because of high contaminated soil of Multan. However, the concentration of $\mathrm{Pb}, \mathrm{Zn}, \mathrm{Cr}$ and $\mathrm{Ni}$ is high in Langra variety. $\mathrm{Cd}$ concentration is quite low in Chaunsa variety and high in Retool variety of mango. Due to excessive uptake of these heavy metals through 
mangoes certain serious health issues are developed. Both $\mathrm{Cr}$ and $\mathrm{Cd}$ act as carcinogens (Table-1).

In urban areas of developing countries industrial developments and urbanization leads to the increased levels of heavy metals in fruits. Since the growth rate in Pakistan is $8 \%$ that results in production of massive amount of urban and industrial wastes that involve in land, water and air pollution so, when mango orchards come in contact with these pollutions level of heavy metals gets elevated [39].

Table-1: Distribution of heavy metals in mangoes grown in three major regions of Pakistan

\begin{tabular}{|l|l|l|l|}
\hline Metals & Multan & Rahim yar khan & Mir purkhas \\
\hline $\mathrm{Fe}$ & $3.70 \pm 0.073^{\mathrm{a}}$ & $2.86 \pm 0.082^{\mathrm{b}}$ & $2.77 \pm 0.090^{\mathrm{b}}$ \\
\hline $\mathrm{Zn}$ & $2.76 \pm 0.054^{\mathrm{a}}$ & $2.10 \pm 0.030^{\mathrm{c}}$ & $2.45 \pm 0.031^{\mathrm{b}}$ \\
\hline $\mathrm{Ni}$ & $6.28 \pm 0.136^{\mathrm{a}}$ & $5.17 \pm 0.191^{\mathrm{b}}$ & $5.38 \pm 0.113^{\mathrm{b}}$ \\
\hline $\mathrm{Cr}$ & $4.44 \pm 0.111^{\mathrm{a}}$ & $4.04 \pm 0.058^{\mathrm{b}}$ & $4.26 \pm 0.113^{\mathrm{ab}}$ \\
\hline $\mathrm{Pb}$ & $1.32 \pm 0.032^{\mathrm{a}}$ & $1.00 \pm 0.031^{\mathrm{b}}$ & $0.95 \pm 0.062^{\mathrm{b}}$ \\
\hline $\mathrm{Cd}$ & $0.22 \pm 0.008^{\mathrm{a}}$ & $0.18 \pm 0.007^{\mathrm{b}}$ & $0.19 \pm 0.008^{\mathrm{b}}$ \\
\hline
\end{tabular}

\section{Heavy metals in watermelon}

Watermelon was originated from Africa and it has been cultivated over a wide area of Middle East countries and it is a vegetable crop. In Asia Iran is the largest cultivator of the watermelon because due to specific climatic conditions watermelon can be produced in it throughout the year. Vegetative growth of water melon is vigorous. For its satisfactorily yield it require nutrients and water that is available at rooting zone. For the cultivation of crop plants wastewater is considered as a main source of water. Because of production of watermelon at large scale large amount of water and nutrient elements are needed so municipal waste water is a main source of fertilizers and water for growth of crops. Heavy metals are mainly found in fruits and vegetables as well as on their surfaces. Prolonged consumption of these heavy metals results in disruption of biochemical and biological processes within human body. They can accumulate in body and ultimately reaches to toxic levels. Cadmium and chromium are considered as carcinogenic elements and may lead to developmental abnormalities in children. In watermelon soil pollution and wastewater irrigation lead to heavy metal deposition [21]. Systematic study reveals that in watermelon cadmium, zinc, chromium, lead, nickel and copper heavy metals are present [42].

\section{Lead effects on brain}

After dietary intake of lead it is introduced in blood stream and 1 to $3 \mathrm{ml} / \mathrm{min}$ is excreted out in bile and urine. The remaining $\mathrm{Pb}$ distributed to soft tissues within body by binding to red blood cells and finally accumulates in our bones. Excessive concentration of lead can damage nervous system either through pharmacological or morphological mechanisms. In morphological effects certain key molecules are disrupted during differentiation, glial cells are prematurely differentiated and neuronal Salic acid production decreased [24].
Lead exposure also results in serious neurological effect called lead encephalopathy with symptoms of memory loss, mental dullness, hallucinations, tremor, paralysis, coma and death. Moreover, decline in motor skills, attention, intelligence, visuospatial skills and language are also closely related neuropshycholological problems [24].

\section{Lead effect on intra-neuronal regulatory mechanisms and neuronal death}

Lidsky \& Schneider. Demonstrated that lead accumulates in mitochondria and damages it so, the disruption of normal function of mitochondria (heam biosynthesis) leads to adverse effects on synaptic transmission within brain [23]. Decreased functioning of mitochondria can also transform normal benign synaptic transmission into neuron-killing excitoxicity regulated by glutamate. Lead not only kills brain cells by inducing apoptosis and excitotoxicity but also produce toxic effects either by lipid peroxidation or oxidative stress. Lead disrupts calcium homeostasis by substituting it. Normally calcium activate second messengers like cyclic AMP, calmodulin, protein kinases and phosphodiesterases but its activity reduced when excess concentration of lead substitute it.

Lead enhances basal release and suppresses calcium dependent release of dopamine, acetylcholine and amino acid neurotransmitters [11]. Calcium ATPase is inhibited while synaptosomal sodiumpotassium ATPase activity is increased by lead. It also disrupt the function of synaptotagmin I protein involve in transmitter release showed that if lead is deposited in brain it cannot remove by using chemical chelating agents and it cannot be eliminated itself because its half-life in brain is approximately 2 years. The impact of lead in blockage of heme shown in Figure-1. 


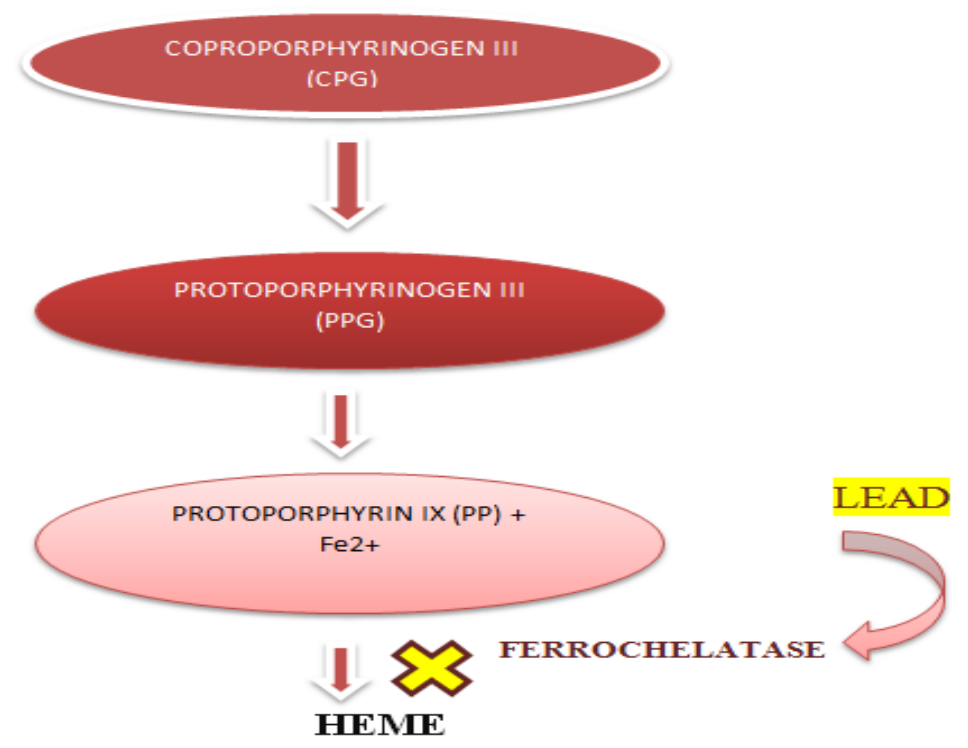

Fig-1: Blockage of heme biosynthesis

\section{Lead effects on children brain}

Children are more sensitive to lead absorption than adults that's why ingested lead is absorbed in large proportion in gastrointestinal tract of children. Large proportion of circulating lead reaches to brain of children and increases the vulnerability of developing nervous system to lead toxicity. In children the initial symptoms of lead poisoning include irritability, lethargy, anorexia and abdominal cramps. Progressively it leads to ataxia, vomiting, clumsiness and coma. If children survive then they will be mentally retarded. Lead poisoning is a syndrome that is associated with lead level in blood $70 \mathrm{mg} / \mathrm{dl}$ and in some children it develops at $50 \mathrm{mg} / \mathrm{dl}[17]$.

Dietary lead also affects the brain by disrupting blood brain barrier. The endothelial cells of capillaries of brain form tight junctions called BBB in which lead uptake is activated by intracellular calcium depletion. Excessive uptake of lead kills brain endothelial cells and disrupts BBB [23].

\section{Lead Effects on Heart}

Lead directly affect smooth muscles of heart vessels by restraining Na-K-ATPase activity and the level of intracellular calcium also raised [18]. Blood pressure might be affected by lead. Bagchi \& Preuss elaborated that when Sprague-Dawley rats have been exposed with $1 \% \mathrm{~Pb}$ acetate in drinking water for about 40 days the systemic blood pressure has been changed. With the continuation of treatment the level of blood pressure gets high and ultimately returned to normal [6]. But its level again elevated when lead exposure ends for several months. This experiment revealed that elevated level of lead in rats lead to reduction of nitric oxide which basically involves in blood pressure regulation, down regulation of guanylatecyclase enzyme that is a nitric oxide activated vasodilation mediator, changes in adrenergenic system [5].

\section{Lead Effect on Kidney}

When level of lead becomes $>60 \mu \mathrm{g} / \mathrm{dL}$ or quite low approximately upto $10 \mu \mathrm{g} / \mathrm{dL}$ it leads to renal dysfunction [16]. There are the two ways of renal toxicity (1) reversibly by serious exposure of $\mathrm{Pb}$ acetate in children (2) irreversibly during interstitial nephropathy results by long term exposure of lead. Lead toxicity causes histopathological changes in renal proximal tubular epithelium and such changes leads to interstitial nephritis that eventually cause hypertension. Lead accumulates in renal cortex and produces both morphological and biochemical evidence of lead poisoning [5].

\section{Lead Effects on Bone}

The primary site for the storage of lead in human body is bones [37]. Two sections of bones are responsible for lead storage. The exchangeable pool which is present at the surface of bone and nonexchangeable pool that is located deeply in bone cortex. Lead easily reaches to plasma from exchange pool and it gets re-absorbed. After leaving from nonexchangeable pool it may be shifted to the surface [33]. By isotope procedure it is estimated that about $40-70 \%$ lead discharge from bones in blood in adults.

About $70 \%$ concentration of lead is stored in soft bones of children while $85-95 \%$ lead is detected in bones of adults. But the exposure of lead acetate $(75 \mathrm{mg} / \mathrm{kg} \mathrm{BW})$ for $20-40$ days leads to hyperplasia associated with proliferation of megakaryocytes. Osteoclasts are not properly absorbed and form mineralized cartilage bars which result in metaphyseal marrow cavity instead of normal healthy bones formation [5].

\section{Lead Poisoning}

Wani demonstrated that vegetables and fruits grown in soils contaminated with lead are also a direct 
source of lead toxicity. Before the development of Environment Protection Agency (EPA) around 1980 the soil has been contaminated due to accumulation of lead through lead paint, emission of lead from gasoline and pipes.

Blood lead concentration from $25-60 \mu \mathrm{g} / \mathrm{dL}$ results in neuropsychiatric effects including irritability, slow conduction of motor nerve, difficulty in attention and headache. When blood level becomes high then $50 \mu \mathrm{g} / \mathrm{dl}$ it gives rise to anemia [17]. Hwang Moreover, blood lead level $>80 \mu \mathrm{g} / \mathrm{dL}$ in adults give rise to abdominal colic and it involve paroxysms of pains Konsett, 2005. Blood level of lead $>100 \mu \mathrm{g} / \mathrm{dL}$ leads to severe manifestations that are closely associated with coma, delirium, seizures, increased pressure in skull and headache [44]. Moreover, in children these menifestations appear when lead level reaches $>70 \mu \mathrm{g} / \mathrm{dL}$. Intense exposure of lead gives rise to neuromuscular and central nervous system menifestations and on continuous exposure it results in gastrointestinal menifestations [44].

Normally, 15\% inorganic lead is absorbed but in pregnant women, children and zinc, iron and calcium deficient individuals its value is higher [20]. Khanjani In adults rate of lead absorption is $94 \%$ but in children its rate is $70 \%$ and it cause severe health problems due to more lead absorption in soft tissues of children. All bone problems are due to long half-life of lead. Normally, its half-life is 40 days and range increases in children because their bones are in developing stage and in pregnant women [7].

\section{Lead Effects on Hemoglobin}

Cell membrane and DNA damage occurs due to heavy metals like lead by reactive free radicals formation. Actually, lead interferes with the functioning of delta-aminolevulinic acid dehydratase enzyme that is essential for heam biosynthesis [44]. Due to interference between lead and heam precursors, these precursors start to build up and directly or indirectly affect neurons [13]. Recent findings revealed that in liver accumulation of organic lead give rise to protein impairment and oxidative imbalance that leads to endoplasmic stress causing liver injuries [12].

\section{Lead Effects on Reproductive System}

Lead effects both male and female reproductive system. When blood lead level increased upto $40 \mu \mathrm{g} / \mathrm{dL}$ sperm count of males has been reduced moreover other activities like morphology of sperm and motility also affected. Lead toxicity in females is more severe and cause low birth weight, miscarriages, childhood development problems and prematurity [32]. As lead is stored in bones but due to some metabolic changes if lead mobilizes from bones in blood it raise the level of lead toxicity. But this process can mitigate by taking increased intake of calcium during pregnancy [44].

\section{Iron Effects on Brain}

In normal aging, brain iron accumulates but in any neurological disorder its amount increases. In case of hemochromatosis iron carrying capability of transferrin increases that increased its transportation against blood brain barrier ultimately iron level in brain cells is elevated. Iron on reacting with hydrogen peroxide produce reactive oxygen species and these easily react with proteins, lipids and DNA [38].

Hemochromatosis occur due deposition of dietary iron in various organs including brain. HFE gene is involved in hemochromatosis. Cys282Tyr mutations in this gene cause various types of iron storage related disorders that might be a cause of Parkinson's disease and Alzheimer's disease. The presence of this HFE protein on ependymal cells, blood vessels and choroid plexus has been increase iron uptake of brain [10].

The evidence of excessive raise in brain iron level leads to $\mathrm{AD}$. The main causes of $\mathrm{AD}$ are amoyloid- $\beta$ (A $\beta)$ plaques formed by impaired clearance and overproduction of $(A \beta)$. Elevated level of iron show interaction with $A \beta$ peptide and reduce molecular oxygen into superoxide and ultimately to hydrogen peroxide by reducing iron. Free iron enhanced oxidative stress that is basically involves in pathogenesis of $\mathrm{AD}$. However, disturbances in iron regulatory protein cause problems in iron decompartmentalization and homeostasis resulting in oxidative processes [38].

\section{Cerebrovascular Disorders}

Intracerebral hematoma is a subclass of stroke that is often fatal. Any disruption in regulation of transferrin, ferritin and transferrin receptors in brain as well as iron overload causes intracerebral hemorrhage [46]. Iron overload can aggravate the damage resulted by ischemic stroke due to generation of ROS and it cause lipid peroxidation [26].

\section{Iron Metabolism}

Any dysregulation in absorption of dietary iron results in iron deficiency or in iron overload. Normally $1-2 \mathrm{mg}$ /day dietary iron is absorbed in duodenum. Main storage organ of iron is liver and liver cells accumulate iron in ferritin or hemosiderin form. Ferritin and hemosiderin form soluble and insoluble iron storage complex. Due to low solubility excretion of iron is quite low in central nervous system [43].

Average amount of iron in human body is 2 $4 \mathrm{~g}$. Iron absorption, recycling and storage is tightly controlled for maintain of normal systemic iron level. Since, iron overload damage the cell [14]. Iron overload is the main cause of alcoholic liver disease and affected almost $50 \%$ of individuals. In ALD iron absorption in intestine has been increased and progressive iron 
overload give rise to lipid peroxidation and oxidative stress ultimately causes liver damage [30].

Milic showed that according to recent findings iron and ferritin overload in $\mathrm{HCV}$ infected patients is $30-40 \%$. Actually, decreased expression of hepcidin due to histone acetylation cause increase in ferroportin expression within the enterocytes as a result iron transport in duodenum is increased, it leads to iron accumulation in liver [27].

Divalent metal transporter-1 and FPN are responsible for iron absorption and iron homeostasis but their disruption leads to iron imbalance. Iron deposition may lead to dysregulation and tissue damage and if untreated it cause cirrhosis and fibrosis [3].

\section{Cadmium Effects}

Cadmium transfer from soil to plant through intracellular transport and cationic exchange within cell membrane so, $95 \%$ of cadmium exposure is occurring through diet [25]. Normal cadmium intake for a person is $10-35 \mu \mathrm{g} /$ day and in adults the cadmium contents are $15-30 \mathrm{mg}$. Due to very long half-life of Cd (10-30 years) its contents are increases with age. Soil contamination by cadmium is due to mining activities, airborne cadmium, usage of $\mathrm{Cd}$ containing fertilizers which ultimately accumulate in vegetables and crops. Mode of uptake is influenced by certain factors like body's age, gender, nutritional status, exposure time and dose [41].

\section{Cadmium Effects on Kidney}

As kidney is main cadmium storage organ so chronic Cd level can cause renal poisoning. About 150200ppm Cd affects kidney. In kidney cadmium binds with metallothionien and reacts easily with cellular component. Any disturbance in phosphate and calcium metabolism which is accompanying cadmium nephropathy leads to kidney stone formation, bone demineralization and bone fractures [8]. Exposure to calcium can show symptoms of calcium loss, renal damage, tubular lesion and proteinuria. Cadmium toxicity can induce nephrotoxicity showing following complications; aminoaciduria, glucosuria, polyuria, hyperphosphaturia and lowered buffering capacity [31]. Long term exposure of even a low dose of cadmium is directly linked to loss of reabsorption activity of kidney for minerals, vitamins and nutrients also called tubular impairment [41]. Generally, level of urinary cadmium reflects body burden for long term exposure and blood $\mathrm{Cd}$ is an indicator of recent exposure [41].

When cadmium binds to metallothionein its concentration increases upto 3000 folds. Cysteinemetallothoinein complex in liver causes hepatotoxicity. On accumulation in kidney tissues it causes nephrotoxicity. $\mathrm{Cd}$ has a binding ability with glutamate, cysteine, histidine and aspartate and give rise to iron deficiency [19].
Persistent exposure of $\mathrm{Cd}$ leads to renal dysfunction because of damaging metallothionein protein [1]. It protects against intracellular cadmium toxicity and act as carrier for $\mathrm{Cd}$ transport to kidney. $\mathrm{Cd}$ harms the renal proximal tubule and also decreases the rate of glomerular filtration [47].

After gastrointestinal absorption $\mathrm{Cd}$ binds to albumin protein and ultimately accumulated in liver where it forms a metallothionein-1 complex. This complex has high affinity for cadmium and when it reaches to kidney it is filtered and accumulates in proximal tubule. Proximal tubule cells carry transporters for both free and bounded form of cadmium thus it interferes with tubules functioning. The level of cadmium increases with the passage of time. Increased cadmium load results in kidney stone formation [47].

\section{Cadmium Effect on Heart}

Cadmium has toxic effects on various organs particularly endothelial cells of heart. It induces improper functioning and structure of cells of heart as well as damage to smooth muscle cells which favors atherosclerotic plaque formation. As compared to nonsmokers, smokers have increased level of cadmium in their blood [41].

\section{Cadmium and DNA Damage}

Cadmium poisoning disrupts cell differentiation, proliferation and apoptosis. These processes interact with repairing mechanism of DNA, inducing apoptosis and generate reactive oxygen species [36]. Cd binds with mitochondria and inhibits oxidative phosphorylation and cellular respiration. Cadmium toxicity cause chromosomal deletions, mutations, depletion of reduced form of glutathione (GSH) and produce ROS like hydrogen peroxide and super oxide ions. Activity of certain antioxidant enzymes like copper/zinc dismutase, catalase and manganese superoxide dismutase is also inhibited by Cd. However, cells that are able to synthesize metallothionein are $\mathrm{Cd}$ resistant and others are sensitive to it [35].

\section{Effects on gastrointestinal tract}

As cadmium is a carcinogenic element according to IARC it involves in production of reactive oxygen species and damage DNA. It lowers the functioning of antioxidant proteins and interferes in DNA repairing mechanisms [15].

It is quite strong and toxic heavy metal and it cannot be destroyed naturally. It gives rise to improper regulation of methyltransferases and aberrant DNA methylation [47].

Nickel Effects
Most of the nickel is distributed to bone,
kidney and lungs after absorption [40]. In


gastrointestinal tract nickel is poorly absorbed approximately $10 \%$. Orally administrated nickel is primarily found in kidneys than other organs. $\mathrm{Ni}^{2+}$ taken through oral route is accumulated in spinal cord than in frontal cortex or cerebellum.

Nickel carbonyl exposure leads to nickel toxicity. Initial symptoms involve respiratory tract infections and other non-specific symptoms. Severe poisoning leads to gastrointestinal and pulmonary toxicity. However, cerebral edema and interstitial pneumonitis are the major causes of death. Nickel compounds and nickel itself are the carcinogenic in nature. Nickel toxicity syndrome is characterized by heart failure, decreased estrogen, asthma, vomiting, stomach irritation, elevated RBCs, headache, nausea, angina, hypoglycemia, lowered pulse, skin rashes and increased urine protein [22].

\section{Effect of Copper on Liver}

Jaundice has partly hepatic origin and is characterized by copper Sulphate toxicity. It appears normally on $2^{\text {nd }}$ or $3^{\text {rd }}$ day after ingestion. Oxidized state of copper leads to liver damage and cause obstruction as well as necrosis. Increased level of bilirubin is directly related to copper poisoning. In mild poisoning level of liver enzymes have also been increases [4].

\section{Kidney and Copper}

Intracellular hemolysis due to copper poisoning is particularly involves in pathogenesis of kidney failure. Due to hemolysis heam pigment also released and copper excreted from red blood cell lysis has direct toxic effects on kidney by damaging tubular epithelial layer. Renal complications have been shown on third or fourth day of poisoning [4].

\section{Effect of Copper on Cardiovascular System}

Cardiovascular collapse occurs in case of severe poisoning as well as tachycardia and hypotension also occurs after few hours of copper exposure. GI blood lose, vomiting and diarrhea are main factors that are normally responsible for hypovolemia. Cardiac dysrhythmia and hypoxic condition occurs in case of severe methaemoglobinemia. Copper toxicity has direct effects on cardiac and vascular cells [4].

\section{Copper and Connective Tissue}

Collagen formation requires copper in proper concentration. Excess level of copper interferes with disulphide bonds of connective tissues and give rise to stretch marks, arthritis osteoporosis and joint problems. Other diseases include muscle weakness, scoliosis and hypnosis. Chronic copper poisoning shows usual symptoms like green lines at teeth base, metallic taste feel in mouth, gastrointestinal problems and progressive emaciation like debility, anemia and malaise [4].

\section{Copper Leads to Wilsons Disease}

Copper accumulation in brain, liver and kidneys leads to Wilson's disease in which ceruloplasmin level is low and unbound form of copper is elevated. This disease characterized by increased copper excretion through urine. Hepatolenticular degeneration occurs due to copper accumulation in brain. In some patients biliary copper excretion is affected that's why copper start to accumulate in body. Normal concentration of copper is $15-55 \mu \mathrm{g} / \mathrm{g}$ in liver but in diseased condition its level is up to $300 \mu \mathrm{g} / \mathrm{g}$. However, copper uptake through cells may be prevented by excessive amount of ascorbic acid and zinc consumption. Other compounds including alphalipoic acid, polyphenols and beta-carotene are also used to reduce oxidative damage caused by copper [47].

Table-2: Effected systems and clinical manifestations of Wilson's disease

\begin{tabular}{|l|l|}
\hline System involved & Clinical manifestations \\
\hline Neurological & Rigidity, tremor, atexia,dyskinesia \\
\hline Opthalmological & Kayser-Fleischer Rings \\
\hline Pshychiatric & Affective disorder, cognitive impairment, behavioral dysfunction \\
\hline Hepatic & Chronic hepatitis, cirrhosis, acute liver failure \\
\hline
\end{tabular}

\section{DNA Damage and Chromium Mutagenicity}

Metabolic intermediates of $\mathrm{Cr}(\mathrm{VI})$ like $\mathrm{Cr}(\mathrm{V})$ and $\mathrm{Cr}(\mathrm{IV})$ and final product chromium (III) form $\mathrm{Cr}$ DNA adducts due to their high reactivity [48]. Chromium-DNA adducts are accumulated in NER deficient cells of human because they are hyper sensitive to chromium toxicity. DNA replication and transcription are inhibited by ternary Cr-DNA adducts. Chromium exposed biological systems have chromosome aberrations and microsatellite instability. The side effects of oral chromium can easily mitigated in gut by reduction however, a specific portion evades the reductive detoxification and finally reaches at target tissue. When chromium (VI) enters into cell it eventually reduced to $\mathrm{Cr}(\mathrm{III})$, which mediates chromium toxicity during reduction by inducing oxidative stress but chromium intermediates interact with DNA and protein [41].

Hexavalent chromium exposure cause acute tubular necrosis which is marked by reduction in urinary flow rate. ATN is generally characterized by renal failure. Research studies by placing $5 \mathrm{ICr}$ intratracheally in animals provide strong evident of 620 fold high chromium accumulation in renal cortex than in liver and RBCs. Trivalent chromium has low 
nephrotoxicity than its hexavalent form and both species of chromium are involved on causing acute renal failure and tubular necrosis [45].

$\mathrm{Cr}$ (VI) facilitates entry in cell and circulation and cellular injury is associated with trivalent form of chromium. Chronic renal injury is generated by long term exposure of minute level of chromium which ultimately leads to chronic interstitial nephritis. The biological half-life of chromium is about 1 month and it gets accumulate in renal tissues over many months. Chromium as a cause of renal failure can only be evident when some conditions are superimposed on other causes of injury such as hypertension, lead nephropathy and reduction in renal reserve [45].

\section{Zinc induced copper deficiency}

High concentration of zinc is associated with deficiency of copper. Competitive absorption with enterocytes is mediated by MT. generally, MT binds through high affinity with copper than zinc, however, high amount of zinc depress copper absorption [34].

\section{Immunological Effects and Zinc}

Sufficient zinc availability is particularly important for immune system. Zinc act as a co-factor for thymulin hormone and also associated with signal transduction in leukocytes. Increased concentration of zinc (above $100 \mu \mathrm{M}$ ) will stimulate monocytes for the secration of pro-inflammatory cytokines as well as inhibit functioning of T-cells. During in vitro process when $>50 \mu \mathrm{M}$ zinc is treated with mixed lymphocyte their alloreactivity is inhibited. Similarly, $80 \mathrm{mg} /$ day zinc for one week also suppresses allogenic immune response. Excess amount of zinc disrupt function of lymphocyte [34].

\section{Impact of Zinc on Apoptosis}

Increased intracellular zinc levels may also induce cell death by inhibition of the energy metabolism. High level of intracellular zinc in different cells and tissues leads to apoptosis. Reports show that intracellular accumulation of zinc either by releasing from intracellular sources or due to exogenous administration activates certain pro-apoptotic molecules such as p38 and potassium channels lead to cellular death. Increased level of intracellular zinc can induce death of cell by inhibiting energy metabolism [34].

\section{Effects on Immune System}

Dietary intake of zinc from 200-400mg/day can disrupt immune functioning. Pancreatic cells have large amount of zinc then other tissues of body so studies reveal that there is an association between zinc and diabetes [47].

\section{CONCLUSION}

In this review we examined the bio toxicity of heavy metals like arsenic, mercury, lead, cadmium, zinc, chromium. Neurological, cardiovascular, ophthalmological, Hepatic, reproductive and psychiatric effects are mainly due to toxic metals. Failure of controlling their exposure to environment may impose adverse effects and lead to severe complications. National as well as international cooperation is required to prevent heavy metal toxicity.

\section{REFERENCES}

1. Adams, S. V., Newcomb, P. A., Shafer, M. M., Atkinson, C., Bowles, E. J. A., Newton, K. M., \& Lampe, J. W. (2011). Sources of cadmium exposure among healthy premenopausal women. Science of the total environment, 409(9), 1632-1637.

2. Alam, S. M., \& Khan, M. A. (2001). Mango-An important fruit of Pakistan. Industry and Economy.

3. Anderson, E. R., \& Shah, Y. M. (2013). Iron homeostasis in the liver. Comprehensive Physiology.

4. Ashish, B., Neeti, K., \& Himanshu, K. (2013). Copper toxicity: a comprehensive study. Research Journal of Recent Sciences ISSN, 2277, 2502.

5. Assi, M. A., Hezmee, M. N. M., Haron, A. W., Sabri, M. Y. M., \& Rajion, M. A. (2016). The detrimental effects of lead on human and animal health. Veterinary world, 9(6), 660.

6. Bagchi, D., \& Preuss, H. G. (2005). Effects of acute and chronic oval exposure of lead on blood pressure and bone mineral density in rats. Journal of inorganic biochemistry, 99(5), 1155-1164.

7. Barbosa Jr, F., Tanus-Santos, J. E., Gerlach, R. F., \& Parsons, P. J. (2005). A critical review of biomarkers used for monitoring human exposure to lead: advantages, limitations, and future needs. Environmental health perspectives, 113(12), 1669.

8. Bernard, A. (2008). Cadmium \& its adverse effects on human health. Indian Journal of Medical Research, 128(4), 557.

9. Chen, Y., Wang, C., \& Wang, Z. (2005). Residues and source identification of persistent organic pollutants in farmland soils irrigated by effluents from biological treatment plants. Environment international, 31(6), 778-783.

10. Connor, J. R. (2003). Iron transport proteins in the diseased brain. Journal of the neurological sciences, 207(1-2), 112-113.

11. Devoto, P., Flore, G., Ibba, A., Fratta, W., \& Pani, L. (2001). Lead intoxication during intrauterine life and lactation but not during adulthood reduces nucleus accumbens dopamine release as studied by brain microdialysis. Toxicology letters, 121(3), 199-206.

12. Fang, J. Y., Wang, P. W., Huang, C. H., Hung, Y. Y., \& Pan, T. L. (2014). Evaluation of the hepatotoxic risk caused by lead acetate via skin exposure using a proteomic approach. Proteomics, 14(21-22), 2588-2599.

13. Fujita, H., Nishitani, C., \& Ogawa, K. (2002). Lead, chemical porphyria, and heme as a 
biological mediator. The Tohoku journal of experimental medicine, 196(2), 53-64.

14. Fung, E., \& Nemeth, E. (2013). Manipulation of the hepcidin pathway for therapeutic purposes. Haematologica, 98(11), 1667-1676.

15. Godt, J., Scheidig, F., Grosse-Siestrup, C., Esche, V., Brandenburg, P., Reich, A., \& Groneberg, D. A. (2006). The toxicity of cadmium and resulting hazards for human health. Journal of occupational medicine and toxicology, 1(1), 22.

16. Grant, L. D. (2008). Lead and compounds. Environmental Toxicants: Human Exposures and Their Health Effects, Third Edition, 757-809.

17. Hayes, A. W. (2007). Principles and methods of toxicology. Crc Press.

18. Hwang, K. Y., Schwartz, B. S., Lee, B. K., Strickland, P. T., Todd, A. C., \& Bressler, J. P. (2001). Associations of lead exposure and dose measures with erythrocyte protein kinase $\mathrm{C}$ activity in 212 current Korean lead workers. Toxicological Sciences, 62(2), 280-288.

19. Jaishankar, M., Mathew, B. B., Shah, M. S., Murthy, K. T. P., \& Gowda, K. R. S. (2014). Biosorption of few heavy metal ions using agricultural wastes. Journal of Environment Pollution and Human Health, 2(1), 1-6.

20. Karri, S. K., Saper, R. B., \& Kales, S. N. (2008). Lead encephalopathy due to traditional medicines. Current drug safety, 3(1), 54-59.

21. Khanjani, M. J., Maghsoudimoud, A. A., Saffari, V. R., Hashamipor, S. M., \& Soltanizadeh, M. (2008, January). Statistical Analysis Of Heavy Metals Concentration In Watermelon Plants Irrigated By Wastewater. In AIP Conference Proceedings (Vol. 971, No. 1, pp. 197-201). AIP.

22. Kumar, S., \& Trivedi, A. V. (2016). A review on role of nickel in the biological system. Int. J. Curr. Microbiol. App. Sci, 5(3), 719-727.

23. Lidsky, T. I., \& Schneider, J. S. (2003). Lead neurotoxicity in children: basic mechanisms and clinical correlates. Brain, 126(1), 5-19.

24. Mason, L. H., Harp, J. P., \& Han, D. Y. (2014). Pb neurotoxicity: neuropsychological effects of lead toxicity. BioMed research international, 2014.

25. McLaughlin, M. J., Whatmuff, M., Warne, M., Heemsbergen, D., Barry, G., Bell, M., ... \& Pritchard, D. (2007). A field investigation of solubility and food chain accumulation of biosolid-cadmium across diverse soil types. Environmental Chemistry, 3(6), 428-432.

26. Mehta, S. H., Webb, R. C., Ergul, A., Tawak, A., \& Dorrance, A. M. (2004). Neuroprotection by tempol in a model of iron-induced oxidative stress in acute ischemic stroke. American Journal of Physiology-Regulatory, Integrative and Comparative Physiology, 286(2), R283-R288.

27. Milic, S., Mikolasevic, I., Orlic, L., Devcic, E., Starcevic-Cizmarevic, N., Stimac, D., ... \& Ristic, S. (2016). The role of iron and iron overload in chronic liver disease. Medical science monitor: international medical journal of experimental and clinical research, 22, 2144.

28. Morais, S., e Costa, F. G., \& de Lourdes Pereira, M. (2012). Heavy metals and human health. In Environmental Health-Emerging Issues and Practice. InTech.

29. Muchuweti, M., Birkett, J. W., Chinyanga, E., Zvauya, R., Scrimshaw, M. D., \& Lester, J. N. (2006). Heavy metal content of vegetables irrigated with mixtures of wastewater and sewage sludge in Zimbabwe: implications for human health. Agriculture, Ecosystems \& Environment, 112(1), 41-48.

30. Mueller, S., \& Rausch, V. (2015). The role of iron in alcohol-mediated hepatocarcinogenesis. In Biological Basis of Alcohol-Induced Cancer (pp. 89-112). Springer, Cham.

31. Nawrot, T., Plusquin, M., Hogervorst, J., Roels, H. A., Celis, H., Thijs, L., ... \& Staessen, J. A. (2006). Environmental exposure to cadmium and risk of cancer: a prospective population-based study. The lancet oncology, 7(2), 119-126.

32. Park, S. K., O’Neill, M. S., Vokonas, P. S., Sparrow, D., Wright, R. O., Coull, B., ... \& Schwartz, J. (2008). Air pollution and heart rate variability: effect modification by chronic lead exposure. Epidemiology

(Cambridge, Mass. ), 19(1), 111.

33. Patrick, L. (2006). Lead toxicity part II: the role of free radical damage and the use of antioxidants in the pathology and treatment of lead toxicity. Alternative Medicine Review, 11(2), 114.

34. Plum, L. M., Rink, L., \& Haase, H. (2010). The essential toxin: impact of zinc on human health. International journal of environmental research and public health, 7(4), 1342-1365.

35. Rahimzadeh, M. R., Rahimzadeh, M. R., Kazemi, S., \&Moghadamnia, A. A. (2017). Cadmium toxicity and treatment: An update. Caspian journal of internal medicine, 8(3), 135.

36. Rani, A., Kumar, A., Lal, A., \& Pant, M. (2014). Cellular mechanisms of cadmium-induced toxicity: a review. International journal of environmental health research, 24(4), 378-399.

37. Renner, R. (2010). Exposure on tap: drinking water as an overlooked source of lead. Environmental health perspectives, 118(2), A68.

38. Sadrzadeh, S. H., \& Saffari, Y. (2004). Iron and brain disorders. Pathology Patterns Reviews, 121(suppl_1), S64-S70.

39. Saeed, A., Safina, N., Sultan, M. T., Seema, M., Muhammad, N., \& Anwaar, A. (2010). Physicochemical attributes and heavy metal content of mangoes (Mangiferaindica L.) cultivated in different regions of Pakistan. Pakistan Journal of Botany, 42(4), 2691-2702.

40. Samal, L., \& Mishra, C. (2011). Significance of nickel in livestock health and 
production. International Journal for Agro Veterinary and Medical Sciences, 5(3), 349-361.

41. Sarkar, A., Ravindran, G., \& Krishnamurthy, V. (2013). A brief review on the effect of cadmium toxicity: from cellular to organ level. Int $J$ Biotechnol Res, 3(1), 17-36.

42. Sun, H., Brocato, J., \& Costa, M. (2015). Oral chromium exposure and toxicity. Current environmental health reports, 2(3), 295-303.

43. Uranga, R. M., \& Salvador, G. A. (2018). Unraveling the Burden of Iron in Neurodegeneration: Intersections with Amyloid Beta Peptide Pathology. Oxidative medicine and cellular longevity, 2018.

44. Wani, A. L., Ara, A., \& Usmani, J. A. (2015). Lead toxicity: a review. Interdisciplinary toxicology, 8(2), 55-64.
45. Wedeen, R. P., \& Qian, L. F. (1991). Chromiuminduced kidney disease. Environmental health perspectives, 92, 71 .

46. Wu, J., Hua, Y., Keep, R. F., Nakamura, T., Hoff, J. T., \& Xi, G. (2003). Iron and iron-handling proteins in the brain after intracerebral hemorrhage. Stroke, 34(12), 2964-2969.

47. Zahra, N., Kalim, I., Mahmood, M., \&Naeem, N. (2017). Perilous effects of heavy metals contamination on human health. Pakistan Journal of Analytical \& Environmental Chemistry, 18(1), 1.

48. Zhitkovich, A. (2005). Importance of chromiumDNA adducts in mutagenicity and toxicity of chromium (VI). Chemical research in toxicology, 18(1), 3-11. 